$\Phi=5$

\title{
Economic growth and under-five malaria mortality in Tanzania mainland: from correlation analysis to causality
}

\author{
Mwoya Byaro $^{1 *}$, Abeli Kinyondo², Patrick Musonda ${ }^{1}$ \\ ${ }^{1}$ School of Public Health, University of Zambia,P.O. Box 50110, Lusaka \\ ${ }^{2}$ Dar-es Salaam University College of Education, Tanzania \\ *Corresponding author E-mail:byaro2014@yahoo.com
}

\begin{abstract}
This paper establishes empirical evidence related with correlation and causality between economic growth (as measured by GDP per capita) and under-five malaria mortality in Tanzania Mainland. The goal is to contribute knowledge on the existing relationship between economic growth and under-five malaria mortality. Correlation and scatter regression analysis plot were employed to find out the relationship among the (GDP per Capita), Insecticides Treated Nets (ITNs) distributed, Human Resources (physicians and nurses) and underfive malaria mortality from the year 2004 to 2015. Moreover, Granger Causality test was applied to test the causal link between the economic growth and under-five malaria Mortality. The economic growth (as measured by GDP per Capita) and number of ITNs distributed under various malaria campaigns have significant unidirectional causality to under-five malaria mortality while there is no causality evidence between human resource for health (physicians and nurses) and under-five malaria mortality despite the observed correlation relationship. Since economic growth and ITNs have unidirectional causal link with under-five malaria mortality, it implies that any changes in GDP per Capita and ITNs will change under-five malaria mortality. The researchers and policy makers need to gather more evidence on ITNs and economic growth to assess the risk of under-five malaria mortality to inform decision making.
\end{abstract}

Keywords: Under-Five Malaria Mortality; GDP Per Capita and Granger Causality Test.

\section{Introduction}

Malaria is a major public health concern for all Tanzanians, especially for pregnant women and children under-five years. It is a leading cause of morbidity and mortality in children under five years and ranks number one in both outpatient and inpatient statistics in Tanzania (NIMR, 2013; Mboera et al., 2007). It is caused by the parasite known as Plasmodium and is transmitted via the bites of infected mosquitoes. The under-five malaria mortality was 113 deaths per 100,000 populations in 2004 while it was 44 deaths per 100,000 populations in 2014 (NMCP, 2016). This trend shows a decrease of under-five malaria mortality by $39 \%$ over the period 2004 to 2014. The country had remarkable gains in child health outcomes for achieving Millennium Development Goals for child survival by 2015(Armstrong et al., 2016). The all cause under-five mortality for instance, has declined from 167 deaths per 1000 live births in 1990 to 53 deaths per 1000 live births in 2013 (World Bank Indicators, 2015). Factors such as child immunization, antenatal care providers, maternal education, skilled birth attendants and ever breastfeeding were associated with lower infant and under-five mortality in Tanzania (Byaro and Musonda, 2016).

Economic development (GDP per capita) leads to improved child health outcomes (Byaro and Musonda, 2017). The indirect pathways that lead income to improved health outcomes include better nutrition, sanitation, housing, education and public health infrastructure (Bhargava et al., 2001; McGuire, 2006). All these factors depend on the level of economic development (Bhargava et al., 2001). Higher incomes support households to spend more on the personal health of the family, which in turn improves the health of the household (Asiedu, 2015). Therefore, economic growth in- creases the average income of individuals, particularly improving the income of the poor people by providing better access to health care services, housing and sanitation leading to lower mortality. Furthermore, economic growth has its roots in technological change, meaning that improvement in technology helps to develop new medicine and improved treatments leading to life longevity (Morand, 2005).

Although some researchers (for example, Bloom and Canning, 2001; Morand, 2005; Robin Swift, 2011) showed that there is a link between economic growth and improved health outcomes (life expectancy), our study concentrate specific on under-five malaria mortality and economic growth (as measured by GDP per capita) to contribute knowledge on the existing body of literature. The study intends to expand our knowledge based on the question: - is there any causal and associative links between economic growth and under-five malaria mortality? A number of studies (for example, Robin Swift, 2011; Bloom et al., 2004) showed that causality runs from health to income. They show that longer life expectancy increase output through labour productivity and capital accumulation. Moreover, Bloom and Canning (2001) argue that, unidirectional and bidirectional causality between health and income can work together at the same time. Other previous literature (for example, Barro, 1991; Sachs and Warner, 1997; Mayer, 2001; Narayan et al., 2010) used cross sectional and panel data to investigate the relationship between health and economic growth. The main finding of these studies is that, health contributes positively to economic growth. On other hand, for instance (Bhargava, 1997; Strauss and Thomas, 1998) examined the impact of health indirectly on economic growth through its effects (nutritional status) on productivity. The findings from these studies conclude that, health contribute positively to productivity. Similarly, other em- 
pirical studies such as (Bhargava et al., 2001; Webber, 2002) uses time series analysis and their main findings showed that health is an important determinant of economic growth. Therefore, there are many studies that show the relationship between per capita income and health outcomes (infant and under-five mortality). Most of these studies however, end with correlation and regression analysis: for instance (Byaro and Musonda, 2017; Deluna and Peralta, 2014; Nishiyama, 2011; McGuire, 2006; Filmer and Pritchett, 1999).

This paper sets out to estimate the correlation between GDP per capita and under-five malaria mortality in Tanzania Mainland, to demonstrate their associations, and to test whether these relationships might be causal. Causality (Granger, 1969) was set out in point of view between under-five malaria mortality and GDP per capita together with other variables that might affect under-five malaria mortality such as number of Insecticide Treated Nets (ITNs) distributed and Human Resources (Physicians and Nurses). Similar variables were used to conduct correlation analysis. Annual time series country level data set from the period 2004 to 2015 was used to set correlation and causality analysis.

Identifying causal relationship among the variables that might influence the under-five malaria mortality can provide strong argument for policy makers to decide priority areas for investment for better child health outcomes (under-five malaria mortality). Our findings show that there is evidence of unidirectional causal link running from GDP per capita to under-five malaria mortality, and from ITNs to under-five malaria mortality. The findings imply that, any variation of ITNs distributed and economic growth (as measured by GDP per capita) have significant effect on under-five malaria mortality. Our findings suggest that, the relationship between under-five malaria mortality and economic growth (GDP per capita); and under-five malaria mortality and ITNs is not only correlational but Granger causal as well. In general, the paper has added new evidence on the unidirectional Granger causality effect from both GDP per capita and ITNs to under-five malaria mortality over the examined time periods.

The rest of the paper is organized as follows. Section 2 introduces the theoretical literature review. In section 3, we set out the estimation techniques including data sources. In section 4, we describe the results of causality and correlation. Section 5 provides the discussion of the results. The last section concludes the paper with policy implications.

\section{Theoretical conceptual framework}

The good health described in (Figure 1) is measured by decline of under-five malaria mortality and the increase of life expectancy). Better health in early childhood can create opportunities for education through investing in schooling which improves the human capital (Labour skills) contributing to economic growth. In turn, poor health can put educational attainment at risk (reverse causality). Good infant health and nutrition directly increase the benefits of education (World Bank, 1993; World Health Organization, 1999b). This implies that, health and education have causal links which stimulate economic growth (Barro, 1991; Barro, 2003). Better health contributes positively to economic growth through productivity because healthy workforces (Labour) are more energetic and mentally fit which in turn raises production (Narayan et al., 2010). Higher wages for health workforces create more consumption and savings which contributes to economic growth. The investments stimulate positively to economic growth through technological diffusion (Podrecca and Carmeci, 2001; Schneider, 2005).

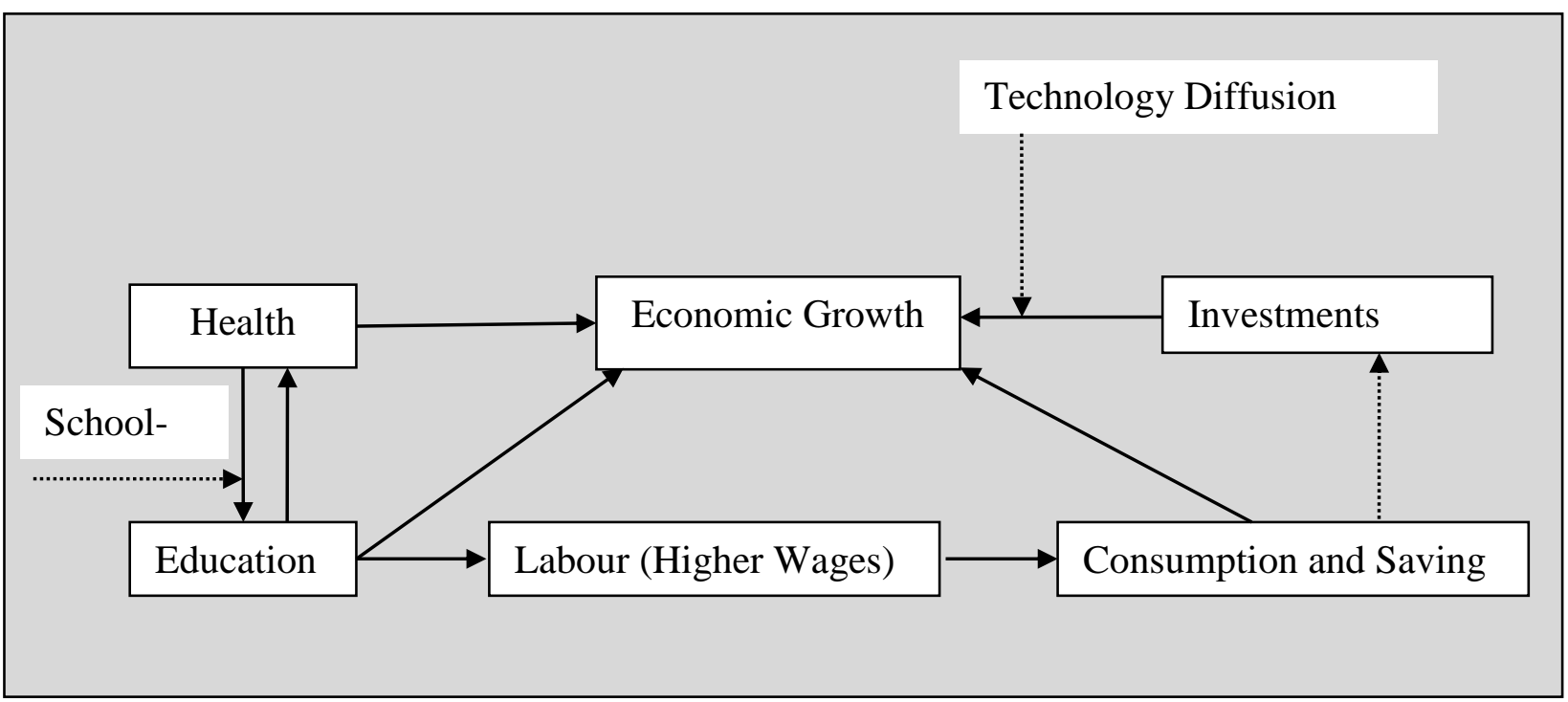

Fig.1: Simplified Conceptual Framework between Health and Economic Growth. Source: (Authors construction).

The conceptual framework above summarizes that; health, education, labour skills and investment contribute positively to economic growth (as measured by GDP per capita). Following this conceptual framework, our aim is to investigate whether there is a reverse causal effect of economic growth (as measured by GDP per capita) on health (decline of under-five malaria mortality).

\section{Methodology}

Ordinary time series correlation analysis was carried out to test association between under-five malaria mortality and GDP per Capita. The human resources for health (physicians and nurses) and ITNs distributed were also used as explanatory or control variables in explaining under-five malaria mortality. The GDP per capita at constant US dollars 2010 was used. The reason to select
GDP per capita was due to factor that, increases in GDP per capita has been associated with better population health outcomes (Gupta et al., 2003). Human Resources (physicians and nurses) were selected as a measure of basic health care provision (McGuire, 2006). Insecticides Treated Nets (ITNs) was selected due to its ability in reducing malaria under-five mortality (Selemani et al., 2016; Okoyo et al., 2015).

The Scatter Plots in log-log forms were drawn to show linear relationship between the variables.

Granger Causality (1969) was used to test the causality among the variables. Causal relations are helpful if the theoretical background is insufficient or experimentation impossible. Thus, the test is conducted when the theory on eventual causal mechanisms connecting the two time series is insufficient or does not exist (Mazriaz, 2015). According to Granger Causality (1980), a time 
series variable A causes B, if the probability of B conditional on its own past history and the past history of A (beside the set of the available information) does not equal the probability of B conditional on its own past history alone. Causal relationship is detected only when parameters are statistically significant and the test is not applied only to econometrics, but also epidemiology and financial analysis (Mazriaz, 2015). Generally, in real sense, the human mind is incapable of recognizing causal relationships. The Granger (1980) concept is based on three assumptions:-

i) The past and the present may cause the future, but the future cannot cause the past.

ii) All knowledge available in the Universe on $t$ contains no redundant information. If some variable $\left(z_{n}\right)$ is functional related to one or more other variables, in a deterministic fashion, then $\left(z_{n}\right)$ should be excluded from all the knowledge available in the universe on $t$.

iii) All causal relationships remain constant in direction throughout time.

Assumption number three was added in order to make a distinction between a random correlation and causation (Stern, 2011) Granger (1980) justifies assumption number three by giving example in a model containing three-time series (number of patients accepted into a hospital on day $t$; number of patients leaving hospital on day $t$; number of ice-cream portions sold in the considered city on day $t$; and claims that the only constant over time dependencies can be suspected to be causal. The temporal correlation between the number of patients leaving the hospital and the number of ice-cream portions sold may however be observed, and these variables may not structurally related and their relationship is probably insignificant if sufficiently long time series are taken into account.

Based on the concepts of Granger causality, Conway et al. (1984) pointed that, 'one could easily produce conflicting conclusions by employing a battery of causality tests on the same data sets'. Thus, it is possible to apply two Granger causality tests to the same data set and obtain different outcomes: one confirming the null and the other rejecting it (Maziarz, 2015). This shows that, the powers of various tests are different and they reject the null hypothesis with different frequencies (Geweke, et al., 1984). This violates the Granger Causality assumption III that, causality is constant in time. The decision to choose the number of lags or information contained in the Akaike Information Criteria (AIC) may lead the researcher using the same Granger Causality test to different conclusions (Maziarz, 2015).

To get the reliable results in Granger Causality, transformation of the data from nonlinearity to linearity must exist. Logarithm transformation is required for data pre-processing (Maziarz, 2015). Empirical time series analysis always faces the problem of nonstationary data. For instance, non-stationary data occur if the variable have stochastic trend at different time periods. For this case, calculating the first difference $\left(\mathrm{x}_{\mathrm{t}}^{\prime}=\mathrm{X}_{\mathrm{t}}-\mathrm{X}_{\mathrm{t}-1}\right)$ is recommended. This improves the quality of the model and influences Granger Causality tests findings (Maziarz, 2015). If Granger Causality detection depends on the time interval used in modeling the data, it means the causal relations relies from data rather than the knowledge if theoretical background is insufficient. In addition, (Maziarz, 2015) presented the standard test of Granger causality to show the dependencies between two variables within one period ahead such as $x_{t}=y_{t+2}$. In general, it is possible to conclude whether a causal relation exists between time series model if theoretical knowledge of the mechanism connecting the time series is accessible (Maziarz, 2015).

\subsection{Sources of data}

Secondary data on under-five malaria mortality and ITNs distributed were collected from the National Malaria Control Programme in Tanzania Mainland. GDP per capita data were collected from the World Bank Development Indicators (2016) while Human Resources for health data were obtained from Human Resources for Health Information System (HRHIS) in the Ministry of Health.
All data collection covered between the years 2004 and 2015. The data was analysed by using Eviews 9 software package.

\subsection{Ethical consideration}

This study used secondary data analysis. This means that, no personal information was available in the data set. However, ethical approval (Reference No: NIMR/HQ/R.8a/Vol. IX/2195) was obtained from the National Institute for Medical Research (NIMR), Tanzania.

\section{Results}

Table 1 show the descriptive statistics of the data transformed into logarithm to make normal distributions to ensure clear relationship between dependent and independent variables to be approximately linear. Moreover, this transformation tends to reduce heteroskedasticity and increases the stationarity of the variables.

Table 1: Descriptive Statistics

\begin{tabular}{lcccll}
\hline & L_ITN & L_U5MR & L_PHY & L_NURSE & L_GDP \\
\hline Mean & 14.38 & 8.69 & 8.95 & 9.64 & 6.55 \\
Median & 14.35 & 8.80 & 8.96 & 9.64 & 6.54 \\
Maximum & 16.48 & 9.31 & 9.36 & 10.17 & 6.73 \\
Minimum & 10.12 & 7.67 & 8.48 & 9.16 & 6.37 \\
Std. Dev. & 1.71 & 0.46 & 0.30 & 0.34 & 0.11 \\
Skewness & -1.17 & -0.80 & -0.10 & 0.05 & 0.02 \\
\hline Observations & 12 & 12 & 12 & 12 & 12 \\
\hline
\end{tabular}

Note: L represent the logarithm, ITN= Number of distributed Insecticides $\mathrm{U} 5 \mathrm{MR}=$ Under Five Malaria Mortality, $\mathrm{PHY}=$ Physicians, GDP= GDP per Capita

Table 2 provides the results for association among GDP per Capita, ITNs distributed, Human Resources (Physicians and Nurses) and under-five malaria mortality. The results show the existence of strong negative and statistically significant correlations between number of physicians, GDP per capita and number of nurses with under-five malaria mortality. This means that, an increase of the number of physicians, nurses and GDP per capita reduces underfive malaria mortality in the country. It was argued that higher GDP per capita (income) leads to better health outcomes through different channels such as, sanitation, education, housing and nutrition (McGuire, 2006; Musgrove 1996, Byaro and Musonda, 2017). The number of ITNs showed negative association with under-five malaria mortality though the estimates were not statistically significant.

Table 2: Correlation between the Variables under Study

\begin{tabular}{|c|c|c|}
\hline \multirow[t]{2}{*}{ Independent Variables } & \multicolumn{2}{|c|}{$\begin{array}{l}\text { Dependent variable } \\
\text { (Under-Five Malaria Mortality) }\end{array}$} \\
\hline & Coefficient & $\mathrm{P}$-value \\
\hline Number of Physicians & -0.89 & $<0.0001$ \\
\hline Number of nurses & -0.90 & $<0.0001$ \\
\hline Number of ITNs distributed & -0.26 & 0.42 \\
\hline GDP per capita & -0.89 & $<0.0001$ \\
\hline
\end{tabular}

Source: (Authors Analysis, 2017).

Furthermore, our findings show that economic growth (as measured by GDP per capita) has significant positive correlation with the number of human resources (nurses and physicians) when GDP per capita act like dependent variables (See Table 3). Countries with higher GDP per capita spend more on health care than countries with lower GDP per capita, and they tend to have larger workforces (Zurn et al., 2004). The persistent shortage of health workers in Tanzania (See Senkoro, 2012; Sirili et al., 2014) can be solved with increasing economic growth. This implies that, in implementing solutions to problems in health care systems and shortage of human resources in developing countries, GDP per capita is an important factor to consider (Kabene et al., 2016). 
Table 3: Correlation between Human Resources and GDP Per Capita

\begin{tabular}{lll}
\hline & $\begin{array}{l}\text { Dependent Variable } \\
\text { (GDP per Capita) }\end{array}$ & \\
Independent Variables & Coefficient & p-value \\
\hline Number of Nurses & 0.996 & $<0.0001$ \\
Number of Physicians & 0.993 & $<0.0001$ \\
\hline
\end{tabular}

Source: (Authors Analysis, 2017).

Figure 2 shows regression scatter plot of variables under study. The graph shows that, the log of under-five malaria mortality appears to be a linear function of the log of the per capita GDP. Under- five malaria mortality decreases with an increase of GDP per capita. This shows that, as the income levels represented by (GDP per capita) in the country increases over time, child health outcomes improve (under-five malaria mortality). The relationship still proves negative relationship between under-five malaria mortality and GDP per capita. Similarly, as log number of Physicians decreases, log of under-five malaria mortality increases. In turn, $\log$ of under-five malaria mortality associate negatively with log of distributed ITNs; however the data points are not close with regression line indicating weak relationship.

(A)

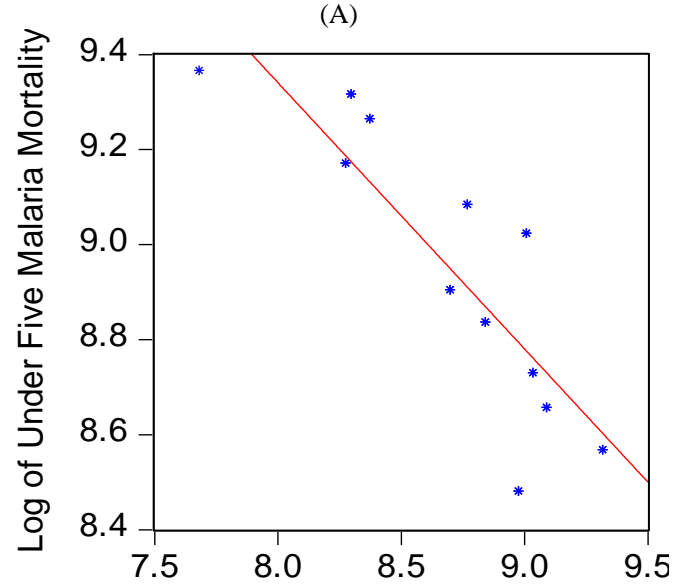

Log of Physcians

(B)

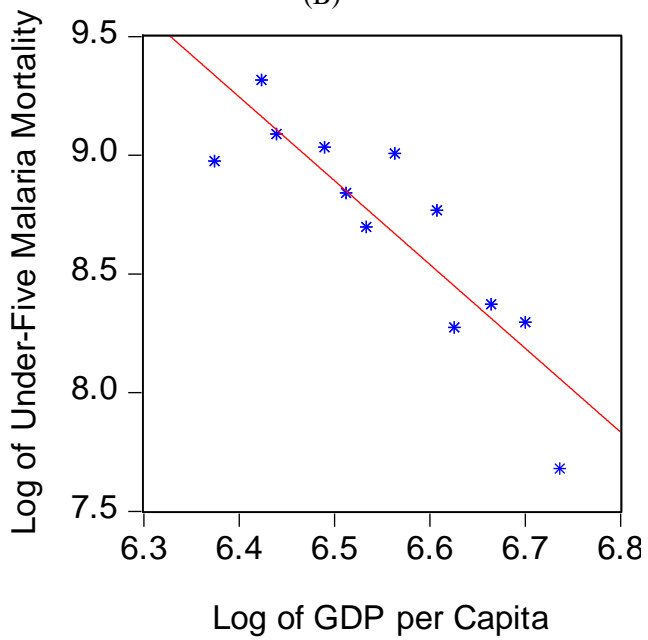

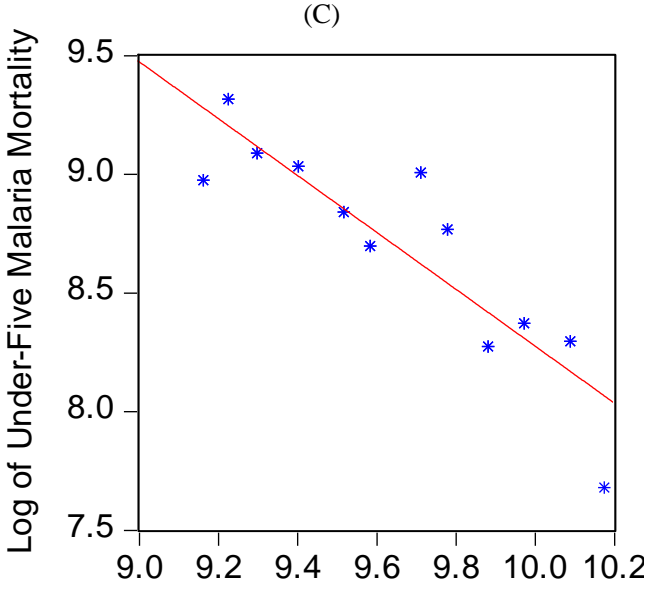

Log of nurses

(D)

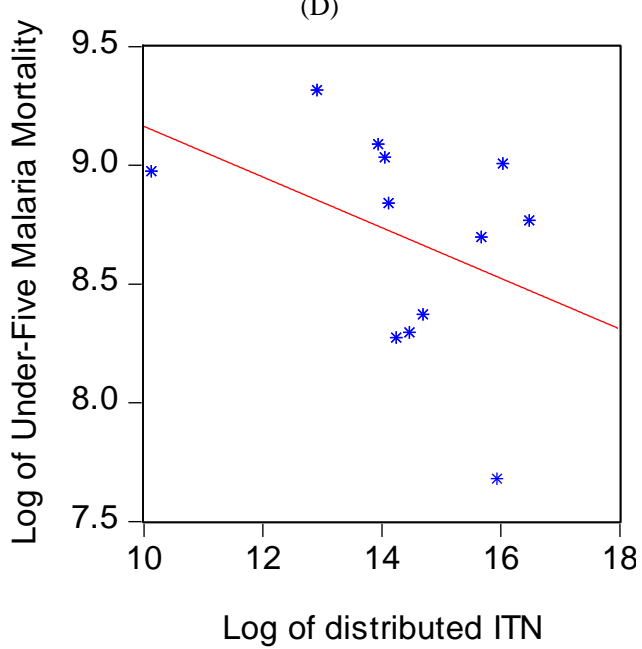

Fig. 2: (A, B, C, D): Regression Scatter Plot showing Relationship of Variables. Source: (Authors Analysis, 2017).

The Granger Causality analysis was tested under the null hypothesis described in Table 4. We used first difference for the variables to become stationary and applied 2 maximum lag orders to conduct the Granger Causality. The null hypothesis showed that the past lagged values of GDP per capita predict/influence the future values of under-five malaria mortality. This means that, the underfive malaria mortality was strongly influenced by the lagged past values of GDP per capita. Similarly, the under-five malaria mortality was also strongly influenced by the past lagged number of Insecticides Treated Nets (ITNs). This means that, the additional information from ITNs and GDP per capita helps explain underfive malaria mortality.

If two variables are correlated (for example, number of nurses and under-five malaria mortality), it is not necessary that one of them causes the other (See Table 4). Therefore, positive or negative correlation in (Table 2 and 3) does not prove causation. Although the number of physicians and nurses are strongly correlated with under-five malaria mortality, under-five malaria mortality has no causal link with nurses and physicians. Table (4) shows that, the Granger causality between GDP per capita and under-five malaria mortality are stronger compared to ITNs. The causality runs from GDP per capita to under-five malaria mortality and from ITNs to under-five malaria mortality. No Granger causality exists between the human resources for health (number of physicians and nurses) and under-five malaria mortality. A bilateral causality might exist if (under-five malaria mortality $\Leftrightarrow$ GDP per capita), meaning that any variation of under-five malaria mortality causes the variation of GDP per capita and vice versa. A Granger causality is unidirectional if (GDP per capita $\mapsto$ under-five malaria mortality), meaning that any variation of GDP per capita has a significant effect on 
under-five malaria mortality. Overally, the Granger causality exists based on the significant of P-value (See Table 4).

Table 4: Pairwise Granger Causality Test

\begin{tabular}{|c|c|c|}
\hline Null Hypothesis & $\begin{array}{l}\text { Observa- } \\
\text { tion }\end{array}$ & $\begin{array}{l}\mathrm{P}- \\
\text { Value }\end{array}$ \\
\hline D(LU5MR) does not Granger Cause D(LNURSE) & 9 & 0.21 \\
\hline D(LNURSE) does not Granger Cause D(LU5MR) & 9 & 0.31 \\
\hline $\mathrm{D}$ (LU5MR) does not Granger Cause D(LGDP) & 9 & 0.63 \\
\hline D(LGDP) does Granger Cause D(LU5MR) & 9 & $\mathbf{0 . 0 3} * *$ \\
\hline D(LU5MR) does not Granger Cause D(LITN) & 9 & 0.74 \\
\hline D(LITN) does Granger Cause D(LU5MR) & 9 & $0.06 *$ \\
\hline D(LU5MR) does not Granger Cause D(LPHY) & 9 & 0.43 \\
\hline D(LPHY) does not Granger Cause D(LU5MR) & 9 & 0.45 \\
\hline D(LGDP) does not Granger Cause D(LNURSE) & 9 & 0.22 \\
\hline D(LNURSE) does not Granger Cause D(LGDP) & 9 & 0.24 \\
\hline D(LPHY) does not Granger Cause D(LGDP) & 9 & 0.80 \\
\hline D(LGDP) does not Granger Cause D(LPHY) & 9 & 0.60 \\
\hline
\end{tabular}

Note: $\mathrm{D}=$ Stationary after first difference, $\mathrm{L}=$ logarithm, U5MR= UnderFive Malaria Mortality, ITN= Insecticides Treated Nets, PHY= Physicians, $\mathrm{GDP}=$ Gross Domestic Product per Capita. Maximum number of lags used $=2$, Then, $* *$ and $*$ significant at $5 \%$ and $10 \%$ levels respectively.

The findings in (Table 4), confirm the unidirectional causal link from economic growth to under-five malaria mortality, and from ITNs to under-five malaria mortality. This means that, any variation of ITNs and GDP per capita has a significant effect on underfive malaria mortality. The interpretations of Granger causality tests in (Table 4) do not provide any evidence on the positive or negative signs of causal effects. Therefore, our evidence suggests that, the links between under-five malaria mortality and economic growth (as measured by GDP per capita); under-five malaria mortality and ITNs are not only correlational but Granger causal as well.

\section{Discussion}

Understanding the correlation and causality between GDP per capita, ITNs distributed, human resources (physicians and nurses), and under-five malaria mortality is important in addressing the burden of total under-five mortality in the country over time. The result showed negatively strong correlation between under-five malaria mortality and GDP per capita $(r=-0.89)$. Also, the number of physicians and nurses were strongly negative related to under-five malaria mortality $(\mathrm{r}=-0.89, \mathrm{r}=-0.90)$ respectively. Therefore, from the year 2004 to 2015 , the reductions of underfive malaria mortality correlated significantly with the increase of GDP per capita, number of physicians and nurses. Our results imply that, health workforce is one of the most important key components of health care systems (Nguyen et al., 2016; Kabene et al., 2006). As the economy continues to grow, there is an expectation of future decrease of more under-five malaria mortality in the country. The economic factors play a role in physicians and nurses participation in the labour market. For instance, as the employer set the wage rate above the equilibrium market conditions, more quantity supplied by skilled workforce (nurses and physicians) leads to surplus. However, as the wage rate is set below the equilibrium market conditions, the employers demand workforce and exist shortage of health workers (nurses and physicians). In order to supply more human resources for health, the government is required to increase the wage rate from its equilibrium conditions that depends on the country economy to fill the gaps of human resources shortages. It means that, though the government demands health personnel, has no capacity to absorb all physicians and nurses (Senkoro, 2012); due to economic and financial constraints. As the country per capita income increases beyond the current situations, we expect more supply of physicians and nurses in the future and better child health outcomes (under-five malaria mortality). Our findings show Granger causality run from GDP per capita to under-five malaria mortality. These results are consistent with (Granados and Ionides, 2008) that found strong evidence of economic growth Granger causing health progress in
Sweden during the $19^{\text {th }}$ and $20^{\text {th }}$ centuries. Moreover, the results reveal that Granger causality run from ITNs to under-five malaria mortality. ITNs protect individuals from mosquito nuisance, suppress the vector population and reduce their ability to transmit malaria and are highly effective in reducing malaria morbidity and mortality (Atieli et al., 2011). However, the insignificant correlation association between ITNs and under-five malaria mortality might be due to usage of ITNs from one household member to other household member which can limit the potential impact of nets (Atieli et al., 2011).

\section{Conclusion}

The aim of this paper was to find out the correlations and Granger causality between economic growths (GDP per capita), human resources (number of physicians and nurses), ITNs and under-five malaria mortality in Tanzania Mainland. We find a strong negative correlation between GDP per capita and under-five malaria mortality. In turn, this correlation shifts to Granger unidirectional causality from GDP per capita to under-five malaria mortality. Similarly, we find a weak and insignificant negative correlation between ITNs and under-five malaria mortality. This correlation shift to unidirectional causality from ITNs to under-five malaria mortality means that, any variation of ITNs distributed has a significant effect on under-five malaria mortality; however this significance is small at $10 \%$ significance level. Our finding implies policy options that aim to boost/increase economic growth to continue reducing the under-five malaria mortality in the country.

This study has got some limitations. Foremost, the study used a small sample size of 12 years which was too short to run time series multiple linear regression models with lagged variables of interest. Short time series data limit the scope for testing richer specifications for the variables of interest. For that case, causality and correlation analysis were used. One of the shortcomings of Granger causality is very sensitive to number of lags in the model and sample period. A lack of sensitivity could be due to lag length choice and small sample. Despite this criticism, the test still has been applied to over 45 thousand studies indexed by the world's most popular scholar papers search engine (Jasco, 2005).

\section{Acknowledgment}

Mwoya Byaro would like to thank INTRA-ACP Mobility Scheme for providing financial support to him during entire Doctorate Programme at the University of Zambia.

Patrick Musonda would like to acknowledge that some of his time is supported by the Research Council of Norway through its Centres of Excellence Scheme to the Centre of Intervention Science in Maternal and Child Health (CISMAC; project number 223269) and through the Global Health and Vac-cinationProgramme (GLOBVAC; project number 248121). In addition, some of his time is also supported by the welcome trust; the Department for International Development; the Alliance for Accelerating Excellence in Science in Africa (DELTAS). Grant Number: [107754/Z/15/Z]. None of these organisations has contributed in any way in writing of this manuscript; any error arising in this publication is thoroughly the author's problem.

\section{References}

[1] Armstrong, C. E., Martinez-Alvarez, M., Singh, N. S., John, T., Magoma, M., \& Holmes, H. A., et al. (2016). Subnational Variation for Care at Birth in Tanzania. Is this Explained by People, Place, Money Or Drugs? BMC Public Health, 16 (2), 795. https://doi.org/10.1186/s12889-016-3404-3.

[2] Asiedu, E., Gaekwad, N. B., Nanivazo, M., Nkusu, M., \& Yi, J. (2015). On the Impact of Income per Capital on Health Outcomes: Is Africa Different? Journal of Economic Literature, JEL F23, D72.

[3] Atieli, H. E., Zhou, G., Afrane, Y., Githeko, A. K., Lee, M. C., Mwanzo, I., et al. (2011). Insecticides Treated Nets (ITN) Owner- 
ship, Usage and Malaria Transmission in the Highlands of Western Kenya. Journal of Parasites and Vectors, 4(1), 113. https://doi.org/10.1186/1756-3305-4-113.

[4] Barro, R. (1991). Economic Growth in a Cross-Section of Countries. Quarterly Journal of Economics, 106(2), 407 443.https://doi.org/10.2307/2937943.

[5] Barro, R. (2003). Determinants of Economic Growth in a Panel of Countries. Annals of Economics and Finance, 4,231-274.

[6] Bhargava, A. (1997). Nutritional Status and the Allocation of Time in Rwandese Households. Journal of Econometrics, 77(1), 277-295. https://doi.org/10.1016/S0304-4076(96)01816-7.

[7] Bhargava, A., Jamison, D.T., Lau, L.J., Murray, C.J.L. (2001).Modeling the Effects of Health on Economic Growth. Journal of Health Economics, 20(3), 423440.https://doi.org/10.1016/S0167-6296(01)00073-X.

[8] Bloom, D.E., Canning, D. \& Sevilla, J. (2004). The Effect of Health on Economic Growth: A production Function Approach. World Development, $32(1)$

13.https://doi.org/10.1016/j.worlddev.2003.07.002

[9] Bloom,D.E., and Canning,D.(2001).Cumulative Causality, Economic Growth, and the Demographic Transition, in Birdsall N.,A.C. Kelley,S.W. Sinding (eds.),2001: Population Matters: Demographic Change, Economic Growth, and Poverty in the Developing World, Oxford: Oxford University Press.https://doi.org/10.3386/w8685.

[10] Byaro, M., \&Musonda, P. (2016). Determinats of Infant and under five mortality Differentials in Tanzanian Zones: Evidence from Panel Data Analysis. Journal of Economics and Sustainable Developments, 7 (18), 113-123.

[11] Byaro, M., \&Musonda, P. (2017). Per Capita Income and Public Health Expenditure: What Makes Good Child Health Outcomes in Tanzania? A comparison between Frequentist and Bayesian Approach (1993-2013). International Journal of Health. 5(1), 74-81. https://doi.org/10.14419/ijh.v5i1.7372.

[12] Conway, Roger, K. et al. (1984). The Impossibility of Causality Testing. Agricultural Economics Research, 36(3), 1-19.

[13] Deluna, R. J., \& Peralta, T. F. (2014). Public Health Expenditures, Income and Health Outcomes in the Philippines. MPRA, 1 20.https://doi.org/10.1186/s12936-015-1031-6.

[14] Filmer, D., \& Pritchett, L. (1999). The Impact of Public Spending on Health: Does Money Matter? Social Science and Medicine, 49 (10), 1309-1323.https://doi.org/10.1016/S0277-9536(99)00150-1.

[15] Geweke, John et al. (1983). Comparing Alternatives Tests of Causality in Temporal Systems: Analytical Results and Experimental Evidence. Journal of Econometrics, 21(2), 161194.https://doi.org/10.1016/0304-4076(83)90012-X.

[16] Granados, J.A.T., \& Ionides, E.L. (2008). The Reversal of the Relation between Economic Growth and Health Progress: Sweden in the 19th and 20th Centuries. Journal of Health Economics, 27(3), 544563.https://doi.org/10.1016/j.jhealeco.2007.09.006

[17] Granger, C.W.J. (1969). Investigation Causal Relations by Econometric Models and Cross Spectoral Methods. Econometrica, 37(3) 424-438.https://doi.org/10.2307/1912791

[18] Granger, Clive W.J. (1980). Testing for Causality. A Personal Viewpoint. Journal of Economic Dynamic and Control, 2(4), 329 352.https://doi.org/10.1016/0165-1889(80)90069-X.

[19] Gupta, S., Verhoeven, M., \&Tiongson, E. R. (2003). Public Spending on Health Care and the Poor. Health Economics, 12, 685-696. https://doi.org/10.4314/thrb.v16i2.6.

[20] Jasco, P. (2005). Google Scholar: The Pros and the cons. Online Information Review, 29(2), 208 214.https://doi.org/10.1108/14684520510598066.

[21] Kabene, S. M., Orchad, C., Howard, J. M., Soriano, M. A., \& Leduc, R. (2006). The Importance of Human Resources Management in Health Care:A Global Context. Human Resources for Health, 4(1), 20.https://doi.org/10.1186/1478-4491-4-20.

[22] Mayer, D. (2001). The Long Term Impact of Health on Economic Growth in Latin America. World Development, 29(6,) 1025-1033. https://doi.org/10.1016/S0305-750X(01)00026-2.

[23] Maziarz, M. (2015). A Review of the Granger Causality Fallacy. The Journal of Philosophical Economics: Reflections on Economic and Social Issues, VIII: 2, 86-105.

[24] Mboera, L. E., Makundi, E. A., \&Kitua, A. Y. (2007). Uncertainty in Malaria Control in Tanzania: Crossroads and Challenges for Future Interventions. American Journal of Tropical Medicine and Hygiene, 77 (6), 112-118. https://doi.org/10.4269/ajtmh.2007.77.112

[25] McGuire, J. W. (2006). Basic Health Care Provision and Under Five Mortality: A cross National study on developing countries. World Development, 34 (3), 405-425. https://doi.org/10.1016/j.worlddev.2005.08.004.
[26] Morand, OF. (2005).Economic Growth, Health, and Longevity in the very long term: Facts and Mechanism, in: Lopez-Casasnovas G, Rivera B, Currais L (eds), Health and Economic growth: Findings and Policy Implications. Cambrige MIT press, Cambrige.

[27] Narayan, P. K., Mishra, S., \& Narayan, S. (2010). Investigating the Relationship between Health and Economic Growth: Empirical Evidence from a Panel of 5 Asian Countries. Journal of Asian Economics, 21(4), 404-411. https://doi.org/10.1016/j.asieco.2010.03.006.

[28] National Malaria Control Programme. (2016). Unpublished Official Malaria Mortality Data.

[29] Nguyen, M. P., Mirzoev, T., and Le, T. M. (2016). Contribution of Health Workforce to Health Outcomes: Empirical Evidence from Vietnam. Human Resources for Health, 14:68.https://doi.org/10.1186/s12960-016-0165-0.

[30] NIMR. (2013). National Institute for Medical Research, the Fourth Tanzania National Health Research Priorities, 2013-2018. Dar es Salaam: National Institute for Medical Research.

[31] Nishiyama, A. (2011). Economic Growth and Infant Mortality in Developing Countries. European Journal of Development Research 23(4), 630-647. https://doi.org/10.1057/ejdr.2011.17.

[32] Okoyo, C., Mwandawiro, C., Kihara, J., Simiyu, E., Gitonga, C. W. \& Noor, A. M. (2015). Comparing Insecticides Treated Bed Net use to Plasmodium Falciparum Infection among Schoolchildren Living near Lake Victoria, Kenya. Malaria Journal, 14(1), 515 https://doi.org/10.1186/s12936-015-1031-6.

[33] Podrecca, E., \&Carmeci, G. (2001). Fixed Investment and Economic Growth: New Results on Causality. Applied Economics, 33(2), 177-182.https://doi.org/10.1080/00036840122890.

[34] Sachs, J., \& Warner, A. (1997). Sources of Slow Growth in African Economies. Journal of African Economies, 6(3), 335-337. https://doi.org/10.1093/oxfordjournals.jae.a020932.

[35] Schneider, P.H. (2005). International Trade, Economic Growth and Intellectual Property Rights. A Panel Data Study of Developed and Developing Countries. Journal of Development Economics, 78(2), 529-547. https://doi.org/10.1016/j.jdeveco.2004.09.001.

[36] Selemani, M., Msengwa, A. S., Mrema, S., Shamte, A., Mahande, M. J., Lutambiz, A. M., et al. (2016). Assessing the Effects of Mosquito Nets on Malaria Mortality Using a Space Time Model: A Case Study of Rufiji and Ifikara Health and Demographic Surveillance System Sites in Rural Tanzania. Malaria Journal, 15(1), 257. https://doi.org/10.1186/s12936-016-1311-9.

[37] Senkoro, E. (2012). Absorption of Health Professional Graduates to the Public Sector Employment:What is The Status? Ministry of Health Social Welfare Human Resource Health Newsletter, 1 (2).

[38] Sirili, N., Kiwara, A., Nyongole, O., Frumence, G., Semakafu, A., \&Hurtig, A. (2014). Addressing the Human Resource for Health Crisis in Tanzania: The lost in transition Syndrome. Tanzania Journal of Health Research, 16 (2). https://doi.org/10.4314/thrb.v16i2.6

[39] Stern, D.I. (2011). From Correlation to Granger Causality. Crawford School Research Paper, (13) 37.https://doi.org/10.2139/ssrn.1959624.

[40] Strauss, J., \& Thomas, D. (1998). Health, Nutrition and Economic Development. Journal of Economic Literature, 36(2), 766-817. http://www.jstor.org/stable/2565122.

[41] Webber, D.J. (2002). Policies to Stimulate Growth: Should we invest in Health or Education? Applied Economics, 34(13), 1633 1643. https://doi.org/10.1080/00036840110115109.

[42] Weil, D. N. (2007).Accounting for the Effect of Health on Economic Growth. Quarterly Journal of Economics, 122(3), 1265-1306. https://doi.org/10.1162/qjec.122.3.1265.

[43] World Bank. (1993). World Development Report, 1993: Investing in Health. New York: Oxford University Press.https://doi.org/10.1596/0-1952-0890-0.

[44] World Bank. (2015). World Development Indicators Database. http:// www.worldbank.org.

[45] World Bank. (2016). World Development Indicators Database. http:// www.worldbank.org.

[46] World Health Organization. (1999b). World Health Report 1999: Making a Difference. Geneva: World health Organization.

[47] Zurn, P., Dal Poz, M.R., Stiwell, B., Adams, O. (2004). Imbalances in the Health workforce. Human Resources for Health, 2(1), 13. https://doi.org/10.1186/1478-4491-2-13. 